\title{
Strategies for the 21st Learning Skills Development of Students in Schools Under the Office of the Basic Education Commission
}

\author{
Kumtorn Wetchasit ${ }^{1}$, Chaiyuth Sirisuthi ${ }^{1} \&$ Pha Agsornsua ${ }^{1}$ \\ ${ }^{1}$ Faculty of Education, Northeastern University, Thailand \\ Correspondence: Chaiyuth Sirisuthi, Faculty of Education, Northeastern University, Thailand. E-mail: \\ chthsirisuthi@gmail.com
}

Received: April 5, 2020

doi:10.5539/ies.v13n10p139
Accepted: June 14, $2020 \quad$ Online Published: September 25, 2020

URL: https://doi.org/10.5539/ies.v13n10p139

\begin{abstract}
The purposes of this research were 1) to study the components and indicators of learning skills in the 21st century of the students, 2) to study the current conditions, desirable conditions and the need for learning skills development in the 21st century of the students, and 3) to develop strategies for the 21st learning skills development of students in schools under the Office of the Basic Education Commission. The samples consisted of 426 administrators and teachers. The instrument was a 5 level rating scale questionnaire with IOC values between 0.80-1.00 with confidence equal to 0.98 . The statistics used were percentage, frequency, mean, standard deviation, modified priority need index ( $\mathrm{PNI}_{\text {modified }}$ ) and matrix analysis. The research results were as follows: 1) Components and indicators of learning skills in the 21st century of the students. There were 3 main components: (1) Learning and innovation skills consisted of 3 sub-components 19 indicators (2) Life and work skills consisted of 5 sub-components 38 indicators (3) Information skills in media, technology consisted of 3 sub-components 28 indicators 2) Current conditions of the 21 st century of the students, in the overall and each aspect were at medium level. In desirable condition, in overall and each aspect were at high level. The priority needs for skills development were life-skills and work, learning skills and innovation, information skills media and technology. 3) Strategies for 21st learning skills development of students in schools under the Office of the Basic Education Commission consisted of the 1st strategy: Speed up the development of life and career skills to keep up with the changes. There were 4 goals, 11 measures, and 14 successful indicators. The 2nd strategy: Continuous learning skills and innovation development included 3 goals, 10 measures, 11 successful indicators. The 3rd strategy: Promote, develop of information skills, media and technology to be up to date included 3 goals, 10 measures, 10 successful indicators.
\end{abstract}

Keywords: strategy, learning skills development, 21st century

\section{Introduction}

World society in the 21st century is an age of globalization which affected many changes. The technology advancement caused huge surge of information and news that affects to people in almost every facet of society, such as economy, society, politics, culture, education, public health, and environment. Thailand, in the 21 st century is therefore affected by the changes in the global society, the process of human development to conform to the changes helped to develop the country. Human development aimed to be knowledgeable, capable, and morally ethical, which will lead the country to progress and live peacefully together (Panich, 2012).

The learners in the 21st century must consist of 3Rs learning skills include Reading, (R) Rriting, and (R) Arithmetic, and $8 \mathrm{Cs}$ which are Critical Thinking and Problem Solving, Creativity and Innovation, Cross Cultural Understanding, Collaboration Teamwork and Leadership, Communication Information and Media Literacy, Career and Learning Self-reliance. These 3Rs, $8 \mathrm{Cs}$ will encourage students to become bachelor in 21stcentury graduates who are ready for life-long learning to learn flexibly throughout their lives to change within themselves (Trilling \& Fadel, 2009). In addition, Sinlarat (2011) states that learners in the 21st century must have the qualifications called the CCPR model, consists of 1) Critical mind 2) Creative mind 3) Productive mind, and 4) Responsible mind which graduated person in the 21 st century need to be responsible. This will be the basis of morality and ethics in accordance with Dejagupt and Kaekan (2011), which commented that the 21st century skills of students, in addition to having 3R7C, must also have E, stand for Ethical Person: a virtue and ethical person. In conclusion, the 21 st century learning skills consisted of $3 \mathrm{Rs}$, $8 \mathrm{Cs}$ and $\mathrm{E}$, which will make 
students ready for long life learning. Therefore, it needed to design learning process in accordance with the current educational direction.

The important factors of educational administration in accordance with the National Education Act is the qualifications or desirable characteristics of the learner which occurred from the school management process that meet the needs and necessities of students in accordance with the context of communities and societies, which Dolprasit (1999) and Muntrong (2002) agreed that providing quality education that meets the needs of service providers, educational standards, and in accordance with the needs of clients by using quality educational administration processes caused students achieved various completed characteristics and client expectations. This caused quality management, creative satisfaction, impressions, and confidence among clients both inside and outside. This also caused for the desired behavioral characteristics of the learners which are educational products through the systematic relationship, namely (1) Factors aspects such as teachers, educational personnel, budget, funds used in educational management, media, materials which included courses or important teaching materials and contents. (2) Process aspects such as teaching and learning process, knowledge transfer and management models that affect the quality of learners and (3) Standards aspects of indicators of educational productivity such as quality learners standards

The basic educational administration level is pre-tertiary education, which the educational institution has to provide from pre-primary level, primary level and secondary level which the school administrators lead in their academic administrations. There are schools affiliated with the office of the National Primary Education Commission. So this research under the Office of the Basic Education Commission will create new knowledge consistent strategies for developing learners' skills in the 21 st century which will be useful in applying in schools for the effectiveness of overall education management in the future.

\section{The Purpose of Research}

1) To study the components and indicators of the 21st century of the students in schools under the Office of the Basic Education Commission.

2) To study the current conditions, desirable conditions and necessary needs of the development of the 21 st century of the students in schools under the Office of the Basic Education Commission.

3) To develop strategies for the development of the 21 st century of the students in schools under the Office of the Basic Education Commission.

\section{Research Methodology}

\subsection{Population, Sample Groups and Data Provider Groups}

1) Population consisted of 2,262 people from 185 schools which are 141 school administrators, 2,121 teachers in primary schools under the Office of Nong Khai Primary Educational Service Area Zone 2.

2) The sample consisted of 103 school administrators, 323 teachers in primary schools under the Office of Nong Khai Primary Educational Service Area 2, which were obtained by using the Krejcie and Morgan's (1970) table and Stratified Random Sampling.

3) Data provider groups, consisting of

a) The groups of data providers were personnel in primary best practices schools under the Office of Nong Khai Primary Educational Service Area 2, from small, medium, and large school. Three person from each school comprising one administrator, one academic chief and one head of teaching and learning section, with the total of 9 persons.

b) Experts who participated in the focus group discussion to consider the appropriateness and made suggestions about the strategies for developing the 21 st century of the students in schools under the Office of the Basic Education Commission.

c) Experts who evaluated suitability, possibility and usefulness of the strategies for the development of the 21 st century of the students in schools under the Office of the Basic Education Commission.

\subsection{The Research Instruments Used in This Research}

1) The interview form regarding the suitability of the components and strategies for the development of learning skills in the 21stcentury of the students in schools under the Office of the Basic Education Commission in all 3 areas, which are 1) learning and innovation skills 2) life skills and career skills 3) Information technology, media and technology skills.

2) Questionnaire with 5 rating scales, inquire about current conditions, desirable conditions of learning skills in 
the 21 stcentury of the students in schools under the Office of the Basic Education Commission in 3 areas are 1) learning and innovation skills 2) life and career skills 3) information technology, media and technology skills reached an IOC between $0.80-1.00$, reliability of 0.98 .

3) 5 levels rating scale assessment form assess the appropriateness, the usefulness, the possibility of the 21 stcentury of the students in schools under the Office of the Basic Education Commission.

\subsection{Research Procedure}

Phase 1: Study of the components and indicators of the 21st century learning skills by using documentary research and assessed suitability by experts as the following steps

Step 1: Study documents and research related to the 21 st century of the students in schools under the Office of the Basic Education Commission to determine the components and indicators of the 21 st century learners' skills.

Step 2: Assess the appropriate components and indicators of the 21st century of the students in schools under the Office of the Basic Education Commission. The following were 9 experts: 1) 3 School director with a doctoral degree or specialist in educational administration 2) 3 teachers with a doctoral degree or expert in curriculum and instruction 3) 3 supervisors who have a doctoral degree in curriculum and instruction or educational administration.

Phase 2: Study current conditions, desirable conditions and the need for the 21st century of the students in schools under the Office of the Basic Education Commission by using the survey research as the following steps.

Step 1: Use the data from Phase 1 to create and find out the quality of the questionnaire and then collected the data from the specified sample group.

Step 2: Analyze current conditions, the desirable conditions of learning skills in the 21st century learning skills by Means, Standard deviation and compared with the criteria. The meaning of Means and analysis of the Modified Priority Need Index (PNI modified) in order to find the sequence of necessary for the 21 st century learning skills development.

Phase 3: Develop strategies for the 21st century of the students in schools under the Office of the Basic Education Commission with the following steps

Step 1: Study Best Practice from schools under the Office of the Basic Education Commission of the Office of Nong Khai Primary Educational Service Area 2 from small, medium, and large sized schools.

Step 2: Use the data from Phase 2 in Matrix Analysis between current and desirable conditions for using to draft strategies.

Step 3: Bring data from steps 1 and 2 into the drafting process as the 21 st century learning skills development strategy. The strategic components consisted of goals, measures, and successful indicators.

Step 4: Examine the appropriateness of the 21st century learning skills development strategy of the school students under the Office of the Basic Education Commission by focus group discussion with 9 experts and raised suggestions for improvement.

Step 5: Assess the appropriateness, usefulness and the possibility of strategies for the development of learning skills in the 21st century of the students in schools under the Office of the Basic Education Commission with 9 experts, including 1) 3 school directors who graduated doctoral degree or specialists, 2) 3 teachers who graduated doctoral degree or specialists 3$) 3$ educational supervisors who graduated doctoral degree.

\section{Results}

Strategic research on the 21st century of the students in schools under the Office of the Basic Education Commission can be summarized as follows:

I) Components and indicators of the 21st century of the students in schools under the Office of the Basic Education Commission consisted of 3 main components, 11 sub-components, 85 indicators are as follows

a) Learning and innovation skills consisted of 3 sub-components which are 1) creativity and technology with 9 indicators 2) critical thinking and problem solving with 6 indicators 3) communication and collaboration with 4 indicators.

b) Life and career skills consisted of 5 sub-components which are 1) flexibility and adaptation with 6 indicators 2) creativity and self-determination with 9 indicators 3) social and cross cultural skills with 6 indicators. 4) Being a builder or producer with 9 indicators. 5) Leadership and responsibility with 8 indicators. 
c) Information technology, media, technology skills with 3 sub-components, including 1) Information technology with 12 indicators 2) Media with 9 indicators 3) Media has 7 indicators.

II) Current conditions of learning skills in the 21st century of the students in schools under the Office of the Basic Education Commission, in overall and each aspect are at a medium level with the priority of learning and innovation skills $(\bar{X}=3.02)$, life and skills $(\bar{X}=2.88)$, information skills in media, technology $(\bar{X}=2.84)$ respectively. Desirable conditions in overall and each aspect are at a high level with the priority of learning and innovation skills $(\bar{X}=3.97)$, life and skills $(\bar{X}=3.92)$, information skills in media, technology $(\bar{X}=3.92)$ respectively. The priority needs for developing skills in are life and career skills, learning and innovation skills, information, media, technology skills respectively.

III) Strategies for the 21 st century of the students in schools under the Office of the Basic Education Commission consisted of:

The 1st Strategy: Speed up the development of life and career skills to keep up with the changes.

Goal 1.1 Students are flexible and adaptable to life and career skills.

\section{Measurement:}

1) Accelerate activities for students to adapt to various roles and duties, including change schedule and context.

2) Accelerate activities for students to practice work to be effective according to the real situation that changes all the time and use the results to be effective.

3) Accelerate activities that promote understanding negotiating and balancing different perspectives and beliefs to accomplish tasks especially in a multi-cultural environment.

4) Accelerate activities that promote positive management with compliments, criticism, and mistakes.

Successful indicators:

1) Percentage of learners which adapted to roles and responsibilities that have changed appropriately.

2) Percentage of learners who have been trained to work successfully and efficiently.

3) Percentage of learners with effective results utilization.

4) Percentage of learners who can understand negotiating and balancing different perspectives and beliefs to accomplish tasks in a multicultural environment.

5) The percentage of learners can manage positively with compliments, criticism and mistakes appropriately.

Goal 1.2 Students are able to think creatively and be themselves.

Measurement:

1) Accelerate activities that promote the ability of learners to deal with various problems in their current society and prepare for adjustment in the future.

2) Accelerate activities that promote the learning of skills in their work and looking for opportunities to learn new things to expand his expertise.

3) Accelerate activities that encourage students to practice in setting goals, assigning tasks, prioritizing work and can complete the work by oneself.

Successful indicators:

1) Percentage of students who are able to deal with various problems in their current society and prepare for adjustment in the future.

2) Percentage of learners who can learn skills in their works and look for opportunities to learn new things to expand one's own expertise.

3) Percentage of learners who can set work goals, specify tasks, arrange the secrets of the tasks that will be done appropriately.

4) Percentage of learners who have successfully achieved the target.

Goal 1.3 Students possess social and cross-cultural skills.

Measurement:

1) Accelerate activities for students to practice in situations that need to respect cultural differences and work 
effectively with people of different social and cultural backgrounds.

2) Accelerate activities that encourage learners to respond generously to different opinions and values.

Successful indicators:

1) Percentage of learners who participate in activities to practice and behave appropriately.

2) Percentage of learners participating in activities and able to respond appropriately to different opinions and values.

Goal 1.4 Learners participate in creating builders or producers.

Measurement:

1) Accelerate activities to encourage learners to actively participate in various work with responsibility, reliability and punctual.

2) Accelerate activities to promote the ability of learners to manage time and projects efficiently.

Successful indicators:

1) Percentage of learners actively participating in various works.

2) Percentage of responsible, reliable and punctual learners.

3) Percentage of learners who are able to manage time and projects efficiently.

Strategy 2: Continuously support and develop learning and innovation skills

Goal 2.1 Students are creative and innovative.

\section{Measurement:}

1) Organize learning activities that promote creative practices with others. Brainstorm for various ideas. Thinking processes derived from many activities. Create and communicate new ideas effectively.

2) Organize learning activities that promote the creation of ideas that are both complementary ideas from the original and new advanced ideas for students to analyze and assess their ideas to improve and develop more creative learning management innovations.

3) Organize activities that bring innovation to initiate the application of ideas to benefit the work that creates new innovations.

4) Promote learning innovations creativity that are appropriate for the learners, planning, designing and developing innovations that are modern and suitable for the learners.

Successful indicators:

1) Percentage of learners who perform creative activities with others and use creative communication.

2) Percentage of learners who participate in brainstorming activities to create various ideas.

3) Percentage of students who are able to create ideas that are both complementary ideas from the original and new progressive ideas.

4) Percentage of learners has applied innovations to benefit work that leads to new innovations.

5) Percentage of teachers who can create learning innovation creatively suits for students.

Goal 2.2 Students possess critical thinking skills and problem-solving skills.

Measurement:

1) Organize activities that promote a process to help learners to find specific thinking errors.

2) Organize activities that promote the ability to think logically and consideration to carefully support decisions in various cases.

3) Arrange activities that promote the ability to draw conclusions, evaluate results from thinking processes, and make decisions to find alternatives to correct problems prudently, appropriately for the situation.

Successful indicators:

1) The level of satisfaction toward process that helps in determining errors in particular thinking.

2) Percentage of students who are able to think logically and consideration carefully to make a decision.

3) Percentage of students who are able to conclude and evaluate results from thinking processes and 
decision-making in solving correct problems roundly appropriately for the situation.

Goal 2.3 School promotes communication and collaboration.

Measurement:

1) Promoting the exchange of ideas through the process by using various conversation, writing and communication skills in any forms in order to gain knowledge, understanding, values, attitudes and desired objectives.

2) Promote communication transfer knowledge, data, facts, explanations, answer questions.

3) Promote communication ability that results in thinking changes Information, knowledge, understanding, and build confidence in oneself effectively.

Successful indicators:

1) Number of activities that encourage the exchange ideas through the process of conversation, writing and communication skills in any kinds in order to gain knowledge, understanding, values, attitudes and desired objectives.

2) Satisfaction level of personnel, learners who communicate, transfer knowledge, information, facts, explanations, and answer questions in schools.

3) Number of activities that enhance communication ability that affect in change, thinking, Information, knowledge, understanding, and build up confidence in oneself effectively.

Strategy 3: Promote, develop of information skills, media and technology to be up to date

Goal 3.1 Students possess information skills.

Measurement:

1) Organize activities to promote the use of information to meet the objectives from the required data source.

2) Organize activities to promote basic understanding regarding ethical or legal issues in accessing and using information.

3) Organize activities to promote plan for information search that use and manage information correctly and creatively.

Successful indicators:

1) Percentage of learners who use information to meet the objectives from the required data source.

2) Percentage of learners who gain knowledge and understanding about ethical or legal issues in accessing and using information.

3) Percentage of learners who are able to plan information searching tasks that use and manage information correctly and creatively.

Goal 3.2 Students possess skills to produce and use media creatively.

Measurement:

1) Organize activities that promote the application of modern media in learning process.

2) Organize activities that promote access to media analysis, evaluate and create in various formats.

3) Organize activities that promote the creation of various suitable medias.

Successful indicators:

1. Percentage of learners who can apply modern media to the teaching and learning process.

2. Percentage of students who can access to media analysis, evaluate, and create media in various formats.

3. Percentage of learners who can create media and present media directly according to objectives.

Goal 3.3 The school possess and serve media, multi-channel technology to students and teachers.

Measurement:

1) Promote the selection of technology to apply in curriculum and learning units.

2) Promote the use of technology to design learning management process, work sheets, submit assignment by using mail groups or other formats. 
3) Promote the use of technology to create assessment and evaluation tools, test bank, organize exam set, manage exams and store data and process, present results in accordance with evaluation measurement regulations.

4) Promote the use of technology as a tool for tracking student progress and behavior.

Successful indicators:

1) Number of media, technologies that are available to students and teachers.

2) The percentage of teachers who use technology to design and organize learning process.

3) Percentage of teachers who use technology to create assessment and evaluation tools.

4) Percentage of teachers who use technology as a tool to monitor student progress and behavior.

\section{Discussion}

The components of the 21 st century of the students in schools under the Office of the Basic Education Commission consisted of 3 components were 1) learning skills and innovation 2) Life skills and career 3) Information skills, media, technology, which assessment results by experts are suitable for all skills. These results may come from all components have been analyzed and synthesized by accepted academic theories and educators which cover the 21 st century learning skills of learners in all areas. The development of the 21 st century learning skills in educational institutions needs to administrate according to all 3 components. At present, world is rapidly progressing due to the trend of social change that occurred in the 21 st century so the 21 st century learning skills are important for living and working in the present social and economic system. In accordance with Panich (2012) mentioned that education in the 21 st century is preparing people to face fast changes, violent, fluctuating and unpredictable. People in this era must have advance skills to learn and adapt. Teachers who work for students must improve themselves to gain enough learning skills as well. They, at the same time, must have skills in the role of teacher in the 21 st century, which is different from the role of teacher in the 20th or 19th century and in accordance with the research of Sirilak (2014) which identify students' skills in the 21st century by synthesizing relevant concepts and research. Then expert in children and youth development of the 21 st century skills found that skills of students in the 21 st century consisted of 5 components which are 1) creativity thinking skills 2) critical thinking and problem solving 3) information skills, media and technology 4) communication skills 5) life and career skills.

The current conditions of the 21st century of the students in schools under the Office of the Basic Education Commission are at a moderate level. The desirable conditions of learners' skills in the 21 st century are at a high level. As for the need for the development of learners' skills in the 21 st century, it was found that the overall average $=0.35$ when considering the skills that need the most in development are life and career skills had a PNI modified value $=0.36$, followed by learning and innovation skills. A PNI modified value $=0.31$, while the skills with the lowest development need were information, media and technology skills. PNI modified value 0.28 . This may be due to the development of learners' skills in the 21 st century is practiced at a medium or low level, resulting in a desirable overall condition. At a high level and life skills and career skills were at the highest need for development. In accordance with the research of Youngtrong (2017) said that strategies for the development of desirable characteristics of students in basic education institutions in the 21 st century, the research found that the conditions and problems of the development of desirable characteristics of students in basic education institutions in the 21 st century, the school determined vision, mission, goals, objectives, measurement, guidelines for knowledge and virtue more than thinking and information, media and technology skills. There is not enough media, technology and learning resources within school for students. There is a little supervision system to manage the learning process. Measurement and evaluation focus on knowledge more than thinking, skills and virtue. Some teachers have less learning management skills in the 21 st century.

Strategies development for the 21 st century of the students in schools under the Office of the Basic Education Commission consisted of 3 strategies, 11 goals, 31 measurements, 35 successful indicators should be discussed as follows:

Appropriate evaluation of the 21st century of the students in schools under the Office of the Basic Education Commission in the high level. The highest average value strategy was continuously developing learning skills and innovation. The lowest average value strategy was information, media and technology skills. These results may come from administrators and teachers were still not keeping pace with the rapid changes in information, media and technology as they should be. There has been an effort to develop learning skills and innovation used in learning management, included in determining work, supervising, tracking, prioritizing and can complete the work by oneself and deal with various problems around in the current society and prepare for adjustment in the future. In accordance with the research of Phamontree (2015) studied the characteristics of school administrators in the 21st 
century according to the perceptions and expectations of teachers under the Office of Educational Service Area 27 found that in relation to interpersonal relationships that the expectation average of the most suitable for subordinates. The school principals were all smiling, polite, and honored the colleagues. The lowest expectation average may come from strengthening leadership in the 21 st century corporate vision. The executives couldn't do all alone. They had to get good cooperation from all subordinates and share understanding with personnel in order to keep the organization vision go forward to lead the organization into the 21 st century effectively.

The possibility assessment results of the 21st century of the students in schools under the Office of the Basic Education Commission in overall were at a more level. When considering each strategy, found that all strategies were at more level. The information, media and technology was at the high level, while the continuous learning and innovation skills development and accelerate the development of life and career skills were as follows. These results may come from administrators and teachers continually emphasized the development of this skill, beginning in the 21 st century until now. Therefore, they used them to meet the objectives from the required data source, understand the fundamentals of ethical or legal issues in accessing and using information, plan information queries that use and manage information correctly and creatively, always use media and technology including information transfer to learners correctly and appropriately. This was in accordance with Chan-klin (2014), said that the current environment is plenty of rapid technological and media advances. We can fully able to access information effectively. In 21 st century, population requires a wide range of abilities especially information technology skills. 3.3 The usefulness evaluation results of the 21 st century of the students in schools under the Office of the Basic Education Commission were in the high level. These results may come from administrators adapted to variety of roles and duties, including changeable schedule and context used to make good use of them, understand, bargain and balance in different perspectives and beliefs in order to accomplish the task. Especially in a multi-cultural environment, the administrators managed positively with compliments, criticism, and mistakes. They have to handle various problems around in the current society and prepare for adjustment in the future. They respond in different opinions and values which is the role of administrators in schools. In accordance with Foi Thong (2018), the way to develop life skills of learners from non-formal and informal education, Nakhon Pathom Province. The results of the research were as follows: 1) Overall life skills of learners were at a more level. 2) Students with different occupations and incomes have different life skills at a significant level of 0.05 . 3) The influenced factors to life skills development were social supported factors, future aim characteristics, family relationships, learning environment, mass community information receiving and friendship between students and friends which can predict life skills development totally at 70.8 percent.

\section{Suggestions}

\subsection{Policy Recommendations}

According to the research results, life and career skills needed to be developed first. Therefore, educational institutions should take this strategy to speed up the development of learning skills in the 21st century of students in the early stages and increase their skills to be close to other skills under the existing resource limitations of school. If there are not any resources limitations, should be developed at the same time but in different emphasis.

According to the research results, it was found that the 21 st century of the students in schools under the Office of the Basic Education Commission the suitability, possibility and benefit in all 3 strategies were at more level. Educational institutions should put into action in order to develop learners to build up necessary skills for living in the 21 st century by putting them in school strategic plan or educational development plan, annual action plan, projects/activities that must be carried out in every year continuously in effective and sustainable results.

The 21st century learning skills were essential characteristics that schools must develop for their students. The Educational Service Area Office should use the research results as a policy for the schools under the supervision to carry out.

\subsection{Suggestions for Further Research}

There should be an evaluation research to monitor, evaluate the success of the implementation of the 21st century learning skills development strategy of the students into the school in order to bring the research results to improve, correct to get suitable strategies for the real context in the future.

The development of the 21 st century learning skills of students, teachers play more important roles. Therefore, there should be research to develop teachers to enhance learning management competency in order to develop the 21 st century learning skills.

There should be participatory action research to develop students' skills in the 21 st century to focus on each skill in the future. 


\section{References}

Chan-klin, N. (2014). A Study of Problems and Quality Management Guidelines for Developing Learners' Skills in the 21st Century, Ban Nern Maprang School, Office of Phitsanulok Primary Educational Service Area Office 2 (Master of education thesis, Educational Administration, Graduate school Pibulsongkram Rajabhat University).

Dejagupt, P., \& Kaekan, P. (2011). Teacher Competency and Guideline of Teacher Development for Social Change. Bangkok, Office of the Education Council.

Dolprasit, S. (1999). Educational Assurance: Power and Hope. Nakhonprathom: National Institute for Teacher, Faculty Staff and Educational Personnel.

Foi Thong, P. (2018). Guidelines for Developing Life Skills of Learners from Non-formal Education and Informal Education Nakhon Pathom Province. Silpakorn Journal of Science Research, 10(2).

Krejcie, R. V., \& Morgan, D. W. (1970). Determining Sample Size for Research Activities. Educational and Psychological Measurement, 30(3), 607-610. https://doi.org/10.1177/001316447003000308

Muntrong, T. (2002). Guidelines for Educational Quality Assurance of Schools under the Jurisdiction of Primary Education, Sop Prap District Lampang Province Chiang Mai. Chiang Mai University.

Panich, W. (2012). The way to create learning for pupils in the 21st century (3rd ed.). Bangkok: Sodsri Foundation.

Phamontree, C. (2015). Characteristics of School Administrators in the 21st Century as Perceived and Expectations of Teachers under the Office of Educational Service Area 27. Journal of Graduate School, 13(6).

Sinlarat, P. (2011). CCPR Model: A New Paradigm Model of Creative and Productive Leaders. Bangkok: Chulalongkorn University Printing House.

Sirilak, W. (2014). A Development of 21st Century Student Skill Indicators (Master of Education Research and Educational Assessment, Graduate School, Naresuan University).

Trilling, B., \& Fadel, C. (2009). 21st Century Skills: Learning for Life in Our Times. San Francisco, CA: John Wiley \& Sons.

Youngtrong, P. (2017). Strategies for Developing Desirable Characteristics of Learners in Basic Education Institutions In the 21st century. Suthiparithat Journal, 31(100).

\section{Copyrights}

Copyright for this article is retained by the author(s), with first publication rights granted to the journal.

This is an open-access article distributed under the terms and conditions of the Creative Commons Attribution license (http://creativecommons.org/licenses/by/4.0/). 